\title{
Effects of defatted yellow mealworm (Tenebrio molitor) on the feed qualities and the growth performance of largemouth bass (Micropterus salmoides)
}

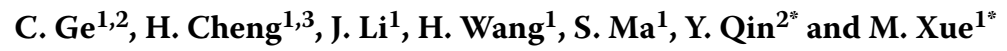 \\ ${ }^{1}$ National Aquafeed Safety Assessment Center, Feed Research Institute, Chinese Academy of Agricultural Sciences, Beijing \\ 100081, China P.R.; ${ }^{2}$ Institute of Animal Science, Chinese Academy of Agriculture Sciences, Beijing 100193, China P.R.; \\ ${ }^{3}$ National Food Institute, Technical University of Denmark, 2800 Kgs. Lyngby, Denmark; qinyuchang@caas.cn; xuemin@caas.cn
}

Received: 12 July 2021 / Accepted: 20 November 2021

(c) 2022 Wageningen Academic Publishers

OPEN ACCESS (c)

\begin{abstract}
The aims of the study were to investigate the effects of inclusion of defatted yellow mealworm (Tenebrio molitor, YM) replacing fishmeal on the pellet qualities of extruded feed and the growth performance of largemouth bass (Micropterus salmoides). Three formulations were used in the experimental diets, with replacing fishmeal at level (wt\%): 0\% (YM0), 50\% (YM50) and 100\% (YM100), respectively. Extrusion trials showed that the expansion rate and porosity of the YM50 feed pellets were higher than that of YM0 $(P<0.05)$. However, the expansion rate and porosity of the YM100 was significantly lower than that of YM0 $(P<0.05)$. Furthermore, the expansion rate, hydration time and hardness of the investigated diets had a strong correlation with the water absorption index and pasting properties of the raw recipe formulations. A total of 300 largemouth bass with about $80 \mathrm{~g}$ of initial weight were randomly distributed into 12 tanks and fed with one of the three isonitrogenous and isoenergetic diets for 8-week. The feeding trials revealed that the feed intake of fish in YM50 group was increased, but it did not compromise fish growth performance. However, the YM100 group had a negative impact on the growth performance of the largemouth bass. The apparent digestibility coefficient $(\mathrm{ADC})_{\mathrm{d}}$ and $\mathrm{ADC}_{\mathrm{e}}$ in the YM50 group were significantly higher than that of other groups $(P<0.05)$. In addition, the hydration time, hardness, expansion rate, microstructure parameters of the investigated diets had a strong correlation with the ADC of nutrients. The present study showed that YM can be used to replace up to $50 \%$ of fishmeal in the diet formulation without compromising the qualities of feed and the growth performance of the largemouth bass. But fully replacement negatively affected the qualities of feed and the growth performance of the fish.
\end{abstract}

Keywords: fishmeal, extruded floating diet, pellet quality of extruded feed, apparent digestibility coefficient

\section{Introduction}

Fishmeal is one of the most important ingredients for aquatic feeds, as it contains high protein content, rich in amino acid composition, fatty acids, vitamins and minerals. It also has a good palatability and high digestibility for aquatic animals (Hardy, 2010; Miles and Chapman, 2006; Tacon and Metian, 2008). In the aquaculture industry, demand for fishmeal is growing with rapid growth in the industry, but its limited availability is putting enormous pressure on a sustainable supply of fishmeal for the aquafeeds (Biswas et al., 2020; Fawole et al., 2020). At present, the continuous reliance on the limited fishmeal in the aquaculture industry may not support the current rapid growth for aquaculture development. Therefore, some sustainable and high-quality 'alternatives' have been found to reduce environmental impacts and costs associated with aquaculture (Tacon and Metian, 2009). With an increase in global demand for food supply, the competition of some common staple food resources between human and animal production systems has been intensified, and non-grain protein sources for animal feeds have become a research hotspot.

As a new source of non-grain protein, insect protein is rich in amino acids, lipids, vitamins and minerals. It 
contains extremely rich crude protein, which similar to the crude protein content of the fishmeal (up to 65\%) (Barroso et al., 2014; Rema et al., 2019; Varotto Boccazzi et al., 2017). Moreover, insect protein has relatively low production requirements and has been assessed to have a lower environmental impact than fishmeal (Smetana et al., 2019). Insect farming can use agricultural co-products and waste-streams as nutritional substrates for insect growth. Thereby, insect farming will reduce environmental pollution and greenhouse gas emissions (Le Feon et al., 2019; Van Huis and Oonincx, 2017).

As a fishmeal replacement, Stenberg et al. (2019) reported a positive effect on the transcription of antioxidant and stressrelated genes in Atlantic salmon leukocytes by replacing fishmeal with black soldier fly in the diet of Atlantic salmon. Henry et al. (2018) demonstrated that replacing fishmeal with yellow mealworm (YM) can reduce the inflammatory response in serum in feeding European sea bass, while it enhanced the innate and adaptive immune response to pathogens. The substitution of fishmeal ingredients also has certain challenges in the extrusion processing of feed pellets. The feed pellets obtained from extrusion should have well-defined porosity and expansion rate leading to specific floatability and hydration time (Glencross et al., 2010). Azzollini et al. (2018) showed that when the mealworm meal replaced $10 \%$ of fishmeal, it significantly improved the micro-structure and expansion rate of the feed pellets. When the replacement was $20 \%$, the feed pellets showed a poor expansion rate, which was mainly due to the fat in the larvae. Irungu et al. (2018) showed that insect meal contains more fat and fibre than that that of fishmeal, and an increase of fat in an extrusion process may affect the feed pellet expansion, and reduce its floatability.

Most studies are aimed at replacing fish meal with fullfat insect larvae, but with a large negative impact on pellet quality (Azzollini et al., 2018; Weththasinghe et al., 2021). Therefore, in order to overcome the processing challenges, defatted insect protein is more suitable for the production of extruded feed (Ottoboni et al., 2018; Rema et al., 2019). Insect protein defatted process mainly includes chemical, physical, or mechanical (Ojha et al., 2021). Different methods have different physiochemical sensorial characteristics and shelf life of YM (Son et al., 2019). Nonetheless, the effect of replacing fishmeal with defatted YM on the physical qualities of extruded pellets and fish performance are still poorly investigated (Ido et al., 2019; Renna et al., 2017).

The aims of the study were to evaluate the effects of defatted YM replacing fishmeal on the physical qualities of extruded floating diet, pellet micro-structure, and growth performance of largemouth bass. It provides an experimental foundation for the application of defatted YM in the aquatic industry. Furthermore, it can also support the development of aquatic industries that are environmentally friendly.

\section{Materials and methods}

\section{Raw materials and extrusion process}

The defatted YM protein used in this study was produced by Guangdong Zehecheng Biotechnology Co. (Guangdong, China). The microwave-dried YM were defatted by the $\mathrm{CO}_{2}$ supercritical extraction method to prepare defatted YM protein (Sipponen et al., 2018). The fishmeal was supplied by Tecnológica de Alimentos S.A., Ltd. (Lima, Peru). Fishmeal was produced from anchovy through the cookingpressing-drying process. The chemical composition and physio-chemical property analysis results of fishmeal and YM are shown in Table 1.

The experimental diets consisted of three formulations with the YM contents at 0\% (YM0), 50\% (YM50) and 100\% (YM100), respectively, all in wt\%. The experimental diet formulations are presented in Table 2.

All diets were produced at a pilot plant of the Chinese Academy of Agricultural Sciences using a twin-screw extruder (TSE65, Yanggong, Beijing, China). In the production, the ingredients were mixed in a tank mixer (CH-100, Zhengtai, Zhejiang, China) for $10 \mathrm{~min}$. After adding water $(29 \%, \mathrm{wt})$ to the diets, the water and diets were allowed to continue mixing for $15 \mathrm{~min}$. Before extrusion processing, the mixed materials need to be left for at least $30 \mathrm{~min}$ to allow an even distribution of water into the raw recipe formulations. The extruder has a twin-screw with diameter as $65 \mathrm{~mm}$, and the length to diameter (L/D) ratio is 20:1. The die plate has two circular $3 \mathrm{~mm}$ holes with an open area of $14.23 \mathrm{~mm}^{2}$. The cutting system was installed in the front of the die plate. The extruder was operated at a constant feed flow rate of $50 \mathrm{~kg} / \mathrm{h}$. The parameters of the extrusion process were given in Table 3.

Table 1. Chemical composition (g/kg, dry matter) and physiochemical properties of fishmeal (FM) and yellow mealworm (YM).

\begin{tabular}{lll} 
& FM & YM \\
Moisture $(\mathrm{g} / \mathrm{kg})$ & 78.0 & 70.0 \\
Crude protein (g/kg DM) & 671 & 668 \\
Crude lipid (g/kg DM) & 98.5 & 38.0 \\
Ash (g/kg DM) & 159 & 84.6 \\
Chitin (g/kg DM) & $\mathrm{ND}$ & 146 \\
Water solubility index (\%) & 3.33 & 18.1 \\
Nitrogen solubility index (\%) & 13.6 & 19.4 \\
\hline${ }^{1}$ ND = not detected. & &
\end{tabular}


Table 2. Formulation and compositions of experimental diets $(\mathrm{g} / \mathrm{kg})$.

\begin{tabular}{|c|c|c|c|}
\hline Ingredients & YMO & YM50 & YM100 \\
\hline Fishmeal $^{1}$ & 485 & 242 & 0.00 \\
\hline Yellow mealworm² & 0.00 & 240 & 480 \\
\hline Cottonseed protein concentrated ${ }^{3}$ & 100 & 100 & 100 \\
\hline Tapioca starch & 50.0 & 50.0 & 50.0 \\
\hline Wheat flour ${ }^{4}$ & 70.0 & 70.0 & 70.0 \\
\hline Wheat gluten meal ${ }^{4}$ & 50.0 & 50.0 & 50.0 \\
\hline Spay-dried blood cell meal & 40.0 & 40.0 & 40.0 \\
\hline a-cellulose & 92.7 & 71.3 & 44.4 \\
\hline $\mathrm{Ca}\left(\mathrm{H}_{2} \mathrm{PO} 4\right)_{2}$ & 6.00 & 13.0 & 25.0 \\
\hline Lecithin oil & 20.0 & 20.0 & 20.0 \\
\hline Fish oil ${ }^{5}$ & 28.1 & 35.7 & 43.2 \\
\hline Soybean oil & 27.9 & 35.0 & 42.0 \\
\hline Kelp powder & 15.0 & 15.0 & 15.0 \\
\hline Choline chloride & 4.00 & 4.00 & 4.00 \\
\hline L-Lys. HCl & 0.00 & 0.90 & 1.70 \\
\hline$D L-M e t$ & 0.00 & 1.30 & 2.40 \\
\hline L-Thr & 0.50 & 1.00 & 1.50 \\
\hline Vitamin and mineral premix ${ }^{6}$ & 9.80 & 9.80 & 9.80 \\
\hline $\mathrm{Y}_{2} \mathrm{O}_{3}$ & 1.00 & 1.00 & 1.00 \\
\hline Total & 1000 & 1000 & 1000 \\
\hline \multicolumn{4}{|c|}{ Nutrient compositions ( $\mathrm{g} / \mathrm{kg}$, at dry matter basis) } \\
\hline DM, dry matter $(\mathrm{g} / \mathrm{kg})$ & 930 & 929 & 929 \\
\hline $\mathrm{CP}$, crude protein (g/kg DM) & 510 & 513 & 516 \\
\hline CL, crude lipid (g/kg DM) & 97.1 & 94.4 & 118 \\
\hline Ash (g/kg DM) & 116 & 100 & 88.0 \\
\hline GE, gross energy (MJ/kg) & 20.7 & 21.0 & 21.0 \\
\hline \multicolumn{4}{|c|}{${ }^{1}$ Fishmeal: anchovy, prime. Tecnológica de Alimentos S.A., Ltd. (Lima, Peru). } \\
\hline \multicolumn{4}{|c|}{${ }^{2}$ Yellow mealworm: Guangdong Zehecheng Biotechnology Co. (Guangdong, China). } \\
\hline \multicolumn{4}{|c|}{${ }^{3}$ Cottonseed protein concentrated: Xinjiang Jinlan Plant Protein Co. Ltd. (Xinjiang, China). } \\
\hline \multicolumn{4}{|c|}{${ }^{4}$ Wheat flour and wheat gluten meal: Changping Nankou Flour Mill (Beijing, China). } \\
\hline \multicolumn{4}{|c|}{${ }^{5}$ Containing tertiary butylhydroquinone $(200 \mathrm{mg} / \mathrm{kg}$ diet) as antioxidant. } \\
\hline \multicolumn{4}{|c|}{ 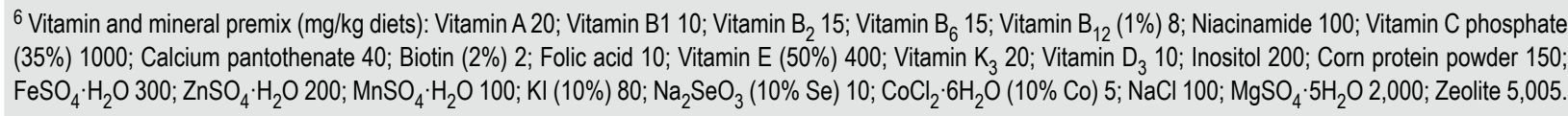 } \\
\hline
\end{tabular}

Table 3. Extruder parameters during the production of experimental diets at three different yellow mealworm (YM) contents.

\begin{tabular}{llll} 
Processing parameters & YM0 & YM50 & YM100 \\
Extrusion zone $1\left({ }^{\circ} \mathrm{C}\right)^{1}$ & & & 100 \\
Extrusion zone $2\left({ }^{\circ} \mathrm{C}\right)^{1}$ & 100 & 100 & 100 \\
Die temperature $\left({ }^{\circ} \mathrm{C}\right)$ & 100 & 100 & 140 \\
Conditioning water content $(\mathrm{wt} \%)^{2}$ & 140 & 140 & 29.0 \\
Screw speed $(\mathrm{rpm})$ & 28.0 & 29.0 & 166 \\
Die diameter $(\mathrm{mm})$ & 166 & 166 & 3.00 \\
Electric current $(\mathrm{Am})$ & 3.00 & 3.00 & 15.0 \\
Throughput $(\mathrm{kg} / \mathrm{h})$ & 12.0 & 11.0 & 53.9 \\
\hline
\end{tabular}

\footnotetext{
${ }^{1}$ Heating the temperature in these parts of the extruder barrel.

${ }^{2}$ Water added in the mixer prior to extrusion. The water content was the actual measured value.
} 
After holding the extrusion process for approximately $15 \mathrm{~min}$ to reach a steady-state, extrudate samples were collected. The extrusion process parameters (i.e. feed flow rate, barrel temperatures in different zones and screw speed) were recorded every $4 \mathrm{~s}$ by a computer system. About $10 \mathrm{~kg}$ extruded pellets were produced in each batch, three replicates were carried out (with an interval of 5 min between replicates). The pellet samples were forced air-dried at room temperature for $48 \mathrm{~h}$. The samples were well sealed and stored at a temperature of $4{ }^{\circ} \mathrm{C}$ for analysis.

\section{Fish experiment and rearing facilities}

During the experiment period, all fishes were maintained in compliance with the Laboratory Animal Welfare Guidelines of China (Decree No. 2 of Ministry of Science and Technology, issued in 1988). A total of 300 largemouth bass were purchased from a single size-graded population (Tianjin Yuqing Aquatic Technology Company, Tianjin, China). All fish were acclimated under laboratory conditions and fed with the YM0 diet for 2 weeks, before the start of the trial. Fish $(80 \pm 0.04 \mathrm{~g})$ were selected after $24 \mathrm{~h}$ of starvation and divided into 12 tanks (256 l) with 25 fish per tank and 4 tanks as one trail group. The fish were fed apparent satiation twice a day at 08:00 and 17:00, respectively, for 56 days. The water conditions of the tanks were maintained at $26 \pm 2{ }^{\circ} \mathrm{C}, \mathrm{pH}=7.4-7.6$, dissolved oxygen $>4.0 \mathrm{mg} / \mathrm{l}$, ammonia nitrogen $0.1 \mathrm{mg} / \mathrm{l}$. Each tank was aerated for $24 \mathrm{~h} /$ day with a photoperiod of 12 D: 12 L. During the feeding period, feed consumption was calculated by recording the weight of feed fed and the number of residual baits per day.

At the end of the feeding trial, the fish in each tank were weighed in batch after $24 \mathrm{~h}$ of starvation. The faeces were collected two weeks after the start of the feeding trial. $\mathrm{Y}_{2} \mathrm{O}_{3}$ was added as an exogenous marker in the experimental diets at $0.1 \%$ (wt\%). The fish were collected at the peak faecal discharge period of 4-10 h after feeding, and the faeces were stored frozen at $-20^{\circ} \mathrm{C}$, then dried at $70^{\circ} \mathrm{C}$ and frozen for chemical analysis.

\section{Physio-chemical properties analysis for raw materials}

\section{Water absorption index and water solubility index}

The water absorption index (WAI) measures the amount of water absorbed by materials. The water solubility index (WSI) is related to the quantity of water-soluble molecules. The WAI and WSI were determined by Anderson (1982) according to the following method. The ingredients and raw recipe formulations were crushed and passed through a 70mesh sieve. The crushed samples $(2.5 \mathrm{~g})$ were suspended in distilled water $(30 \mathrm{ml})$ and placed in a $50 \mathrm{ml}$ centrifuge tube. The suspension was stirred intermittently and centrifuged at $3,000 \times g$ for $10 \mathrm{~min}$. The supernatant was poured into an aluminium cup and dried at $135^{\circ} \mathrm{C}$ for $2.5 \mathrm{~h}$. The weight of the remaining gel in the centrifuge tube was measured, and the WAI and WSI were calculated as follows:

WAI $(\%)=\frac{W_{g}-W_{d s}}{W_{d s}} \times 100$

WSI $(\%)=\frac{W_{S S}}{W_{d s}} \times 100$

where $\mathrm{W}_{\mathrm{g}}$ is the weight of colloid in the centrifuge tube after centrifugation $(\mathrm{g}), \mathrm{W}_{\mathrm{ds}}$ is the weight of sample $(\mathrm{g}), \mathrm{W}_{\mathrm{ss}}$ is the weight of dry matter in the Petri dish after drying (g).

\section{Nitrogen solubility index}

The nitrogen solubility index (NSI) was determined in three replicates according to the AACC approved method 46-23 with minor modifications (AACC, 1995). The samples (1 g) were weighed into $50 \mathrm{ml}$ centrifuge tubes and added $30 \mathrm{ml}$ of water, mechanically shaken at room temperature for $30 \mathrm{~min}$ and then centrifuged at $3,000 \times \mathrm{g}$ for $10 \mathrm{~min}$. The supernatant was collected and analysed for nitrogen by the standard Kjeldahl method in combination with the supernatant. NSI is the percentage of the measured nitrogen content divided by the protein content of the ingredients and raw recipe formulations.

\section{Pasting properties (peak-viscous and final-viscous)}

We used the method modified by Ragaee et al. (2006) to determine the pasting properties. The pasting properties of the raw recipe formulations were measured using a Rapid Visco-Analyzer (RVA, Perten, NSW, Australia). 5 g raw material sample and $25 \mathrm{ml}$ (plus moisture adjustment) of distilled water were added to the sample canister and shaken for $5 \mathrm{~s}$ to disperse the sample. The Standard 1 temperature profile was used for the test procedure. Each treatment was tested in triplicate.

\section{Oil absorption capacity}

$2.5 \mathrm{~g}$ of sample raw recipe formulations was weighed into a $50 \mathrm{ml}$ centrifuge tube and mixed well with $30 \mathrm{ml}$ of soybean oil. The mixture was centrifuged at $3,000 \times g$ for $10 \mathrm{~min}$ at $4{ }^{\circ} \mathrm{C}$. The excess oil was removed after centrifugation and weighed (Samuelsen et al., 2014). The oil absorption formula was calculated as follows.

$\mathrm{OAC}(\%)=\frac{W_{g}-W_{d s}}{W_{d s}} \times 100$

where $\mathrm{W}_{\mathrm{g}}$ is the weight of colloid in the centrifuge tube after centrifugation $(\mathrm{g}) ; \mathrm{W}_{\mathrm{ds}}$ is the weight of dry matter sample (g). 


\section{Physical qualities of extruded floating diet analysis}

\section{Bulk density $(B D)$}

The standard bulk density instrument (GHCS-1,000 series, Hangzhou Maizhe Instrument Co., Ltd., Zhejiang, China) with a capacity of 1 litre filled with feed pellets was weighted. The measurement was run in triplicate and reported as the average.

\section{Water stability}

The method modified by Baeverfjord et al. (2006) was used to determine the water solubility/stability. $10 \mathrm{~g}$ feed pellets samples $\left(\mathrm{M}_{1}\right.$, accurate to $\left.0.1 \mathrm{~g}\right)$ were placed in a $500 \mathrm{ml}$ glass beaker in a steel-mesh cage and filled with water to a depth of $5.5 \mathrm{~cm}$. The beaker was shaken in a water bath at $25^{\circ} \mathrm{C}$ for $20 \mathrm{~min}$ and then dried at $135^{\circ} \mathrm{C}$ for $2 \mathrm{~h}$. The weight $\left(\mathrm{M}_{2}\right)$ of the pellets was measured after drying. The water stability (WS, \%) was calculated as:

$\mathrm{WS}(\%)=\frac{M_{1} \times(1-x)-M_{2}}{M_{1} \times(1-x)} \times 100$

where $M_{1}$ is the weight of the feed pellets before the test; where $M_{2}$ is the weight of the feed pellet after drying; where $\mathrm{x}$ is the water content of the sample before measurement (as a weight percentage), measured by standard method.

Three replicates were taken for each group of samples and the average value was used as the result.

\section{Oil absorption capacity and oil leakage}

The oil absorption capacity (OAC) measures the amount of oil absorbed by feed pellets. The oil leakage (OL) reflects the ability of pellets to store oil. As described by Samuelsen and Oterhals (2016), a $100 \mathrm{~g}\left(\mathrm{~A}_{1}\right)$ pellet sample was weighed and placed in the measuring cup of a laboratory vacuum sprayer, which was subsequently emptied of air. Excess soybean oil was sprayed to the measuring cup and mixed followed by a slow release of air over a period of $3 \mathrm{~min}$. The pellets were removed from the measuring cup. Excess oil was removed by lightly gently compressing the pellets with oil-absorbing wipes. The weight of the pellets was recorded $\left(B_{1}\right)$.

Oil leakage was measured in samples from the oil absorption capacity analysis. The samples were placed on absorbent paper and stored at $40{ }^{\circ} \mathrm{C}$ for $24 \mathrm{~h}$. Record the weight of the sample $\left(\mathrm{B}_{2}\right)$ and calculate the amount of oil leakage.

Three replicates were taken for each group of samples and the average value was used as the result. The Oil absorption capacity and oil leakage were calculated according to the following formula.

$$
\begin{aligned}
& \operatorname{OAC}(\%)=\frac{B_{1-A_{1}}}{A_{1}} \times 100 \\
& \mathrm{OL}(\%)=\frac{B_{2-B_{1}}}{A_{1}} \times 100
\end{aligned}
$$

\section{Pellet hardness}

Pellet hardness was measured using a Texture-Analyzer (TA-XT2, Model 1000 R, Stable Micro Systems, Blackdown Rural Industries, Surrey, UK), fitted with a $25 \mathrm{~kg}$ load cell and a principal component-operated remote control. The test probe $(\mathrm{P} 10,10 \mathrm{~mm})$ was axially pressed on the pellet at a constant speed $(0.8 \mathrm{~mm} / \mathrm{s})$ to achieve $60 \%$ compression. The major break of the pellet (the peak force) was measured and presented in Newton $(\mathrm{N})$. Measurements were conducted for 20 pellets from each batch of the feed pellet samples and reported as the average (Samuelsen and Oterhals, 2016).

\section{Expansion rate}

Twenty pellets were randomly selected from each batch of samples. Their diameters were measured with a digital caliper. The average value of the ratio of the pellet diameter to the die hole diameter $(3.0 \mathrm{~mm})$ was taken as the expansion rate (Umar et al., 2013).

\section{Hydration time}

According to a method of Wang et al. (2021), 150 pellets as one sample batch were placed in a $500 \mathrm{ml}$ beaker containing $400 \mathrm{ml}$ of distilled water at room temperature. Starting count time, two pellets were removed from the beaker every minute and cut to observe their cross-sections. When the pellet cross-section is completely soaked with water, and no hardcore, the time was recorded as the hydration time of the pellet. Three replicates from each batch of feed pellet samples were measured and reported as mean values.

\section{Floatability}

No less than 150 pellets were randomly selected and placed in a $500 \mathrm{ml}$ beaker, containing $400 \mathrm{ml}$ of distilled water at room temperature. After 30 minutes, the number of pellets floating on the surface of the water was recorded, with three replicates for each sample. Floatability (\%) was calculated as: $\mathrm{N}_{1} / \mathrm{N} \times 100$. Where $\mathrm{N}_{1}$ is the number of floating pellets after 30 minutes; $\mathrm{N}$ is the total number of pellets in the water (Khater et al., 2014).

\section{Pellet durability index}

The measurement was performed using a standard method ASAE S269.4 (Mina-Boac et al., 2006). A 500 g pellet sample was placed in a pellet durability tester (ST136, Shengtai, Jinan, China). The equipment was run for $10 \mathrm{~min}$. The sample was removed, sieved (i.e. greater than $5.60 \mathrm{~mm}$ ), and the remaining pellet was weighed. The pellet durability 
index (\%) was calculated as: $\mathrm{Z}_{1} / \mathrm{Z}_{0} \times 100$. Where $\mathrm{Z}_{1}$ is the weight of feed pellet after the test; $Z_{0}$ is the weight of the feed pellet before the test.

\section{Micro-structure}

The micro-structure characteristics of the feed pellets were analysed by scanning electron microscopy (SU3500, Hitachi, Tokyo, Japan). Feed pellets were cut with a blade and adhered to a holder using carbon adhesive tabs, and then gold sprayed with a vacuum ion jet (JEOL FineCoat JFC-1100, Tokyo, Japan) for $45 \mathrm{~s}$. In the high vacuum mode, the gold-sprayed sample was observed with a Scanning electron microscopy at a voltage of $3 \mathrm{kV}$. The microstructure parameters such as pore area and total porosity of the feed pellets were analysed using Image J software provided by the National Institutes of Health, Washington DC, USA (Ahmed et al., 2010; Banjac et al., 2021). Three replicates from each batch of feed pellet samples were measured.

\section{Chemical analysis}

The dry matter of diets and faeces were analysed by drying the samples at $105^{\circ} \mathrm{C}$ to a constant weight. Crude protein was determined by Kjeldahl method using a Kjeldahl nitrogen tester (K1100F, Hanon, Shandong, China) (AOAC, 2006). The crude fat diets and faeces were acid hydrolysed with Soxtex system HT 1047 hydrolysis unit followed by extraction of crude fat with Soxtex system 1043 (Foss, Hillerød, Denmark). The ash of diets was analysed by combustion in a muffle furnace (CWF1100, Carbolite, Derbyshire, UK) at $550{ }^{\circ} \mathrm{C}$ for $3 \mathrm{~h}$. The gross energy of the diets and faeces were determined using an IKAC2000 calorimeter (C2000, IKA, Staufen, Germany). The inert marker $\left(\mathrm{Y}_{2} \mathrm{O}_{3}\right)$ of the diets and faeces was analysed using inductively coupled plasma atomic emission spectrometry at Guobiao (Beijing) Testing \& Certification Co., Ltd. (Beijing, China).

\section{Statistical analysis}

The experimental data were expressed as the mean \pm standard deviation (SD). All data were analysed by SPSS 22 software (IBM Corp., Armonk, NY, USA). Data were checked for normality and homogeneity of variances, followed by ANOVA or Kruskal-Wallis test when appropriate. The significant data were compared by Duncan's method for comparison of means, with differences considered significant at $P<0.05$. Linear and quadratic polynomial comparisons were used to evaluate the relationship between different levels of YM replacement of fishmeal. The correlation between the expansion rate and water stability of extruded pellets with physio-chemical properties of the raw recipe formulations were analysed using the software OriginPro 2021 (OriginLab Corporation, Northampton, MA, USA).

\section{Results}

\section{Physio-chemical properties of the raw recipe formulations}

The physio-chemical properties of the raw recipe formulations are presented in Table 4. Table 4 shows that there was a significant difference in the water absorption index between the groups $(P<0.05)$, the raw recipe formulation of YM50 had the highest value, and the YM100 had the lowest values. The water solubility index in the raw recipe formulation of YM50 was significantly higher than YM0 $(P<0.05)$. The nitrogen solubility index in the diets of YM50 and YM100 were significantly higher than the YM0 group $(P<0.05)$. As the level of YM increased, the peak-viscous increased from 269 to $408 \mathrm{cp}$, and the final-viscous increased from 299 to $324 \mathrm{cp}$. There were no significant differences in the oil absorption capacity between the diets $(P<0.05)$.

Table 4. Physio-chemical properties of the raw recipe formulations at three different yellow mealworm (YM) contents (means \pm $\mathrm{SD}, \mathrm{n}=3)^{1}{ }^{1}$

\begin{tabular}{llll} 
& YM0 & YM50 & YM100 \\
Water absorption index (\%) & & & $143 \pm 0.2^{\mathrm{a}}$ \\
Water solubility index (\%) & $147 \pm 0.8^{\mathrm{b}}$ & $152 \pm 1.1^{\mathrm{c}}$ & $7.08 \pm 0.9^{\mathrm{ab}}$ \\
Nitrogen solubility index (\%) & $5.85 \pm 0.4^{\mathrm{a}}$ & $8.75 \pm 0.5^{\mathrm{b}}$ & $14.8 \pm 0.2^{\mathrm{b}}$ \\
Oil absorption capacity (\%) & $14.4 \pm 0.1^{\mathrm{a}}$ & $14.8 \pm 0.1^{\mathrm{b}}$ & $87.4 \pm 3.7$ \\
Peak-viscous (cp) & $87.6 \pm 1.7$ & $86.3 \pm 2.7^{\mathrm{b}}$ & $408 \pm 6.2^{\mathrm{c}}$ \\
Final-viscous (cp) & $269 \pm 4.0^{\mathrm{a}}$ & $339 \pm 3.8^{\mathrm{b}}$ & $324 \pm 2.7^{\mathrm{b}}$ \\
\hline
\end{tabular}

${ }^{1}$ Values (mean \pm SD) in the same row with different superscript letters are significantly different $(P<0.05)$. 


\section{Physical qualities of extruded floating diet}

The physical qualities of the extruded floating diet with an increased level of YM are presented in Table 5. The data in the Table 5 indicate that the bulk density, hardness, and hydration time of YM0 and YM50 diets were significantly lower than the diet YM100 $(P<0.05)$. And the oil absorption capacity of YM0 and YM50 diets were significantly higher than the diet YM100 $(P<0.05)$. There were significant differences in the expansion rate of the feed qualities between the groups $(P<0.05)$, the diet YM50 had the highest value, and the diet YM100 had the lowest values. There was no significant difference in floatability between the groups $(P>0.05)$, and the floatability was $100 \%$ in all diets.

\section{Micro-structure of feed pellets}

The micro-structure of feed pellet pore and quantitative micro-structural parameters of the feed pellets are presented in Figure 1A and Table 6, respectively. Figure 1A clearly shows the differences in micrographs of feed pore size and porosity with the addition of YM. In Figure $1 \mathrm{~A}$, the red areas represent the void pores, whereas the continuous solid matrix, mainly the pore walls is gray (nonpores). The yellow areas represent the shape edge of void pores. The feed pellet of diet YM50 was the largest and most aerated one, followed by YM0. The diet YM100 reduced the pore area and overall porosity of the feed pellets. Table 6 clearly shows the differences in microstructural parameters between the three diets. The pore area and total porosity of the diet YM50 were obviously higher than that of YM0 and YM100 $(P<0.05)$. There was a significant difference in the pore counts for the three diets $(P<0.05)$, the YM0 diet had the highest value, and the YM100 had the lowest value. Furthermore, an increase of the YM content in diets had a strong quadratic relationship with the pore area and porosity of the feed pellets $(P<0.01)$. The pore counts are linearly decreased with increasing YM content in diets $(P<0.01)$.
The pore size distribution of the feed pellets is presented in Figure 1B. It shows that the diet YM0, YM50, and YM100 have a pore area between $0.009-0.091 \mathrm{~mm}^{2}, 0.018-0.3288$ $\mathrm{mm}^{2}$, and $0.045-0.4725 \mathrm{~mm}^{2}$, respectively. Similarly, the pore area of the diets increases with an increase of YM content in diet formulations.

\section{Growth performance and apparent digestibility coefficients}

The growth performance of the largemouth bass is given in Table 7, where 3 different diets with 3 levels of YM contents were applied. The final body weight (FBW) and specific growth rate (SGR) of the YM0 and YM 50 groups were significantly higher than that YM100 group $(P<0.05)$. There was a significant difference in the feed conversion ratio (FCR) between the groups $(P<0.05)$, the YM100 group had the highest value, and the YM0 group had the lowest value. According to ANOVA, there were no differences in FI between the three groups $(P>0.05)$.

The apparent digestibility coefficients (ADC) of nutrients in the largemouth bass are given in Table 7. The $\mathrm{ADC}_{\mathrm{p}}$ and $\mathrm{ADC}_{1}$ of the $\mathrm{YM} 0$ and $\mathrm{YM} 50$ groups were obviously higher than that of the YM0 group $(P<0.05)$. The $\mathrm{ADC}_{\mathrm{d}}$ and $\mathrm{ADC}_{\mathrm{e}}$ of the YM50 group were obviously higher than that of the YM0 and YM100 groups $(P<0.05)$.

According to the linear polynomial contrasts, the increase in the levels of YM in diets has a strong linear correlation with the FBW, SGR, and FCR of the largemouth bass $(P<0.05)$. An increase of YM content in diets had a significant linear relationship with the $\mathrm{ADC}_{\mathrm{d}}$ and $\mathrm{ADC}_{\mathrm{e}}(P<0.01)$. Furthermore, a strong quadratic relationship was found between dietary YM levels and $\mathrm{ADC}_{\mathrm{d}}(P<0.01)$. The Linear and quadratic relationships were observed between dietary YM levels and $\mathrm{ADC}_{1}(P<0.01)$.

Table 5. Physical qualities of extruded floating diet at three different yellow mealworm (YM) contents (means $\pm S D, n=3$ ). ${ }^{1}$

\begin{tabular}{|c|c|c|c|}
\hline & YMO & YM50 & YM100 \\
\hline Bulk density (g/l) & $374 \pm 1.3^{a}$ & $366 \pm 0.3^{a}$ & $431 \pm 0.3^{b}$ \\
\hline Water stability (\%) & $4.10 \pm 0.1^{\mathrm{a}}$ & $4.76 \pm 0.1^{b}$ & $4.54 \pm 0.1^{b}$ \\
\hline Oil absorption capacity (\%) & $64.1 \pm 0.8^{b}$ & $65.4 \pm 1.0^{\mathrm{b}}$ & $48.2 \pm 0.0^{\mathrm{a}}$ \\
\hline Oil leakage (\%) & $11.13 \pm 0.0^{b}$ & $10.92 \pm 0.1^{b}$ & $9.94 \pm 0.1^{\mathrm{a}}$ \\
\hline Hardness (N) & $86.4 \pm 2.6^{a}$ & $93.3 \pm 4.6^{\mathrm{a}}$ & $129 \pm 3.6^{b}$ \\
\hline Expansion rate (\%) & $1.36 \pm 0.0^{b}$ & $1.39 \pm 0.0^{c}$ & $1.26 \pm 0.0^{\mathrm{a}}$ \\
\hline Hydration time (min) & $41.9 \pm 0.7^{a}$ & $42.2 \pm 0.7^{a}$ & $59.6 \pm 0.1^{b}$ \\
\hline Floatability (\%) & $100 \pm 0.0$ & $100 \pm 0.0$ & $100 \pm 0.0$ \\
\hline Pellet durability index (\%) & $98.6 \pm 0.1^{a}$ & $98.5 \pm 0.0^{\mathrm{a}}$ & $98.7 \pm 0.0^{b}$ \\
\hline
\end{tabular}

${ }^{1}$ Values (mean $\pm \mathrm{SD}$ ) in the same row with different superscript letters are significantly different $(P<0.05)$ 
A

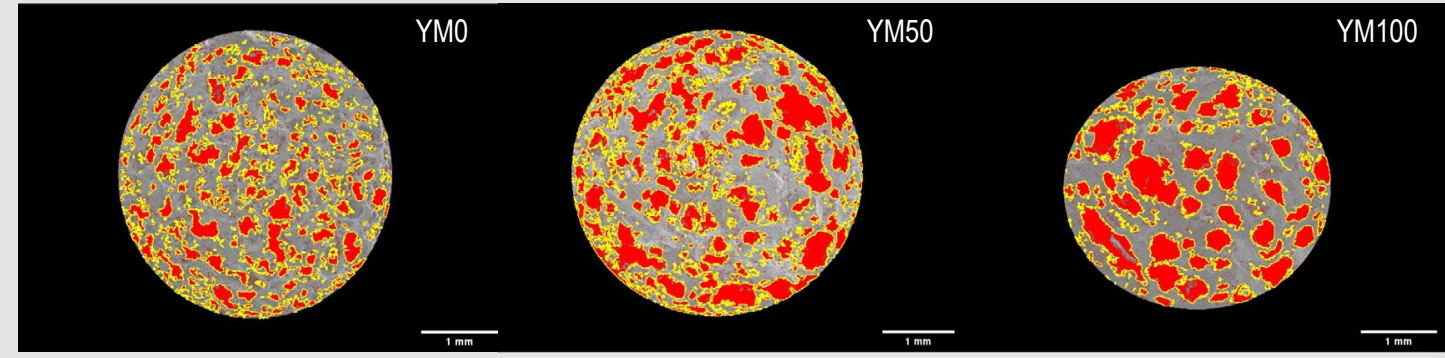

B

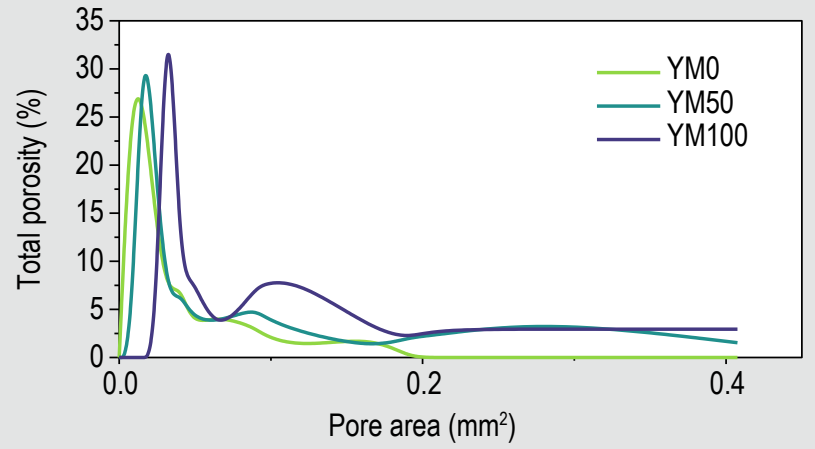

Figure 1. Microstructure of feed pellets. (A) microscopy image feed pellets at three different yellow mealworm (YM) contents. YM substituted different levels of fishmeal 0\% (YM0); 50\% (YM50); 100\% (YM100). (B) pore size distribution of the feed pellets (average from three replicates) with increased level of YM. The microstructural parameters such as pore area and total porosity of feed pellets were analysed by ImageJ software, and then the plots were represented by the software OriginPro 2021 software. The red areas represent the void pores. The pore walls is gray (non-pores). The yellow areas represent the shape edge of void pores.

Table 6. Scanning electron microscopy results for the microstructural parameters of feed pellets at three different yellow mealworm (YM) contents (means $\pm S D, n=3$ ). ${ }^{1,2}$

\begin{tabular}{lllllll} 
& YM0 & YM50 & YM100 & $\boldsymbol{P}_{\text {ANoVA }}$ & $\boldsymbol{P}_{\text {linear }}$ & $\boldsymbol{P}_{\text {quad }}$ \\
Pore area $\left(\mathrm{mm}^{2}\right)^{3}$ & $4.01 \pm 0.1^{\mathrm{a}}$ & $5.69 \pm 0.0^{\mathrm{b}}$ & $3.96 \pm 0.1^{\mathrm{a}}$ & 0.000 & 0.696 & 0.000 \\
${\text { Total porosity }(\%)^{4}}^{\text {Pore counts }}$ & $35.5 \pm 0.9^{\mathrm{a}}$ & $38.1 \pm 0.3^{\mathrm{b}}$ & $33.5 \pm 0.7^{\mathrm{a}}$ & 0.009 & 0.081 & 0.005 \\
\hline
\end{tabular}

${ }^{1}$ Values (mean $\pm \mathrm{SD}$ ) in the same row with different superscript letters are significantly different $(P<0.05)$.

${ }^{2} P_{\text {ANOVA }}=P$-value of one-way ANOVA; $P_{\text {linear }}$ and $P_{\text {quad }}$ are the $P$-values of the linear and quadratic components of the polynomial comparison analysis of each parameter with increased level of $Y M$.

${ }^{3}$ Pore area $\left(\mathrm{mm}^{2}\right)$ : the area of pores in feed pellets.

${ }^{4}$ Total porosity (\%): the percentage of the pore area divided by the total area of the feed pellets.

${ }^{5}$ Pore counts: the number of pores in the feed pellets.

\section{Correlation analysis}

(physio-chemical properties of the raw recipe formulations, physical qualities of extruded floating diet, micro-structure of feed pellets and nutritional data)

The correlation analysis between the physical qualities of extruded floating diet with physio-chemical properties of the raw recipe formulations are presented in Figure 2A and Table S1. Both clearly show that the WAI was significantly positively correlated with the expansion rate, pore area and total porosity $(P<0.05)$, and negatively correlated with hydration time and hardness $(P<0.05)$. The WSI of the raw recipe formulations had a strong positive correlation with the water stability and pore area of the diets $(P<0.05)$. The Pasting properties ( $\mathrm{PV}$ and FV) of the raw recipe formulations had a strong positive correlation with the hydration time and hardness of the diets $(P<0.05)$, and negatively correlated with expansion rate and total porosity $(P<0.05)$. 
Table 7. Growth performance and apparent digestibility coefficient (ADC) of nutrients (\%) in largemouth bass, fed by experimental diets at three different yellow mealworm (YM) contents (means $\pm S D, n=4$ ). ${ }^{1,2}$

\begin{tabular}{|c|c|c|c|c|c|c|}
\hline & YMO & YM50 & YM100 & $P_{\text {ANOVA }}$ & $P_{\text {linear }}$ & $P_{\text {quad }}$ \\
\hline \multicolumn{7}{|l|}{ Growth performance } \\
\hline Final body weight (FBW) $(\mathrm{g})^{3}$ & $179 \pm 3.6^{\mathrm{b}}$ & $169 \pm 2.9^{\mathrm{b}}$ & $143 \pm 4.7^{\mathrm{a}}$ & 0.00 & 0.000 & 0.131 \\
\hline Specific growth rate (SGR) (\%/day) $)^{4}$ & $1.44 \pm 0.0^{\mathrm{b}}$ & $1.34 \pm 0.0^{\mathrm{b}}$ & $1.08 \pm 0.1^{a}$ & 0.00 & 0.000 & 0.101 \\
\hline Feed intake $(\mathrm{Fl}, \% \mathrm{BW} / \mathrm{d})(\%)^{5}$ & $1.52 \pm 0.1$ & $1.59 \pm 0.1$ & $1.51 \pm 0.0$ & 0.398 & 0.877 & 0.189 \\
\hline Feed conversion ratio $(\mathrm{FCR})^{6}$ & $1.10 \pm 0.0^{\mathrm{a}}$ & $1.22 \pm 0.0^{\mathrm{b}}$ & $1.44 \pm 0.0^{c}$ & 0.00 & 0.000 & 0.169 \\
\hline \multicolumn{7}{|l|}{$A D C$ of nutrients } \\
\hline $\mathrm{ADC}_{d}(\%)^{7}$ & $71.4 \pm 0.5^{\mathrm{a}}$ & $74.3 \pm 0.4^{b}$ & $72.1 \pm 0.7^{\mathrm{a}}$ & 0.011 & 0.400 & 0.004 \\
\hline $\operatorname{ADC}_{p}(\%)^{8}$ & $88.1 \pm 0.2^{b}$ & $88.1 \pm 0.1^{b}$ & $86.1 \pm 0.7^{\mathrm{a}}$ & 0.011 & 0.008 & 0.071 \\
\hline $\operatorname{ADC}_{e}(\%)^{9}$ & $77.4 \pm 0.6^{\mathrm{a}}$ & $79.3 \pm 0.2^{b}$ & $76.6 \pm 0.7^{\mathrm{a}}$ & 0.012 & 0.317 & 0.005 \\
\hline $\mathrm{ADC}_{1}(\%)^{10}$ & $95.0 \pm 0.4^{b}$ & $94.5 \pm 0.3^{b}$ & $89.0 \pm 0.5^{\mathrm{a}}$ & 0.000 & 0.000 & 0.001 \\
\hline
\end{tabular}

${ }^{1}$ Values (mean $\pm \mathrm{SD}$ ) in the same row with different superscript letters are significantly different $(P<0.05)$.

${ }^{2} P_{\text {ANOVA }}=P$-value of one-way ANOVA; $P_{\text {linear }}$ and $P_{\text {quad }}$ are the $P$-values of the linear and quadratic components of the polynomial comparison analysis of each parameter with increased level of $Y M$.

${ }^{3}$ FBW: final body weight;

${ }^{4}$ SGR (specific growth rate, $\left.\%\right)=100 \times[\ln ($ FBW/initial body weight) $] /$ days.

${ }^{5} \mathrm{FI}$ (feed intake, \% body weight/day) $=100 \times$ total feed consumption $(\mathrm{g}) /\left[\left(\mathrm{W}_{\mathrm{i}}+\mathrm{W}_{\mathrm{f}}+\mathrm{W}_{\mathrm{d}}\right) / 2\right] /$ days.

${ }^{6} \mathrm{FCR}$ (feed conversion ratio) $=$ feed intake $/\left(W_{f}+W_{d}-W_{i}\right) . W_{f}$ is the final total weight; $W_{d}$ is the total weight of dead fish; $W_{i}$ is the initial total weight; $n=4$.

${ }^{7} A D C$ of $D M\left(A D C_{d}\right)(\%)=\left(1-D_{B} / D_{B}{ }^{\prime}\right) \times 100 \%, D_{B}$ is the content of marker in feed, $D_{B}{ }^{\prime}$ is the content of marker in faeces.

${ }^{8} A D C$ of $C P\left(A D C_{p}\right)(\%)=\left[1-\left(C_{A} / C_{A} \times C_{B} / C_{B}{ }^{\prime}\right)\right] \times 100 \% . C_{A}$ is the protein content of the feed, $C_{A}$ is the amount of protein in the faeces, $C_{B}$ is the content of marker in feed, $C_{B}$ is the content of marker in faeces.

${ }^{9} A D C$ of $G E\left(A D C_{e}\right)\left[1-\left(G_{A}{ }^{\prime} / G_{A} \times G_{B} / G_{B}\right)\right] \times 100 \%$. $E_{A}$ is the energy content of the feed, $E_{A}$ is the amount of energy in the faeces, $E_{B}$ is the content of marker in feed, $E_{B}$ is the content of marker in faeces.

${ }^{10} \mathrm{ADC}$ of $C L\left(A D C_{\mid}\right)(\%)=\left[1-\left(L_{A}{ }^{\prime} / L_{A} \times L_{B} / L_{B}{ }^{\prime}\right)\right] \times 100 \%$. $F_{A}{ }^{\prime}$ is the fat content of the feed, $F_{A}$ is the amount of fat in the faeces, $F_{B}$ is the content of marker in feed, $F_{B}$ is the content of marker in faeces.
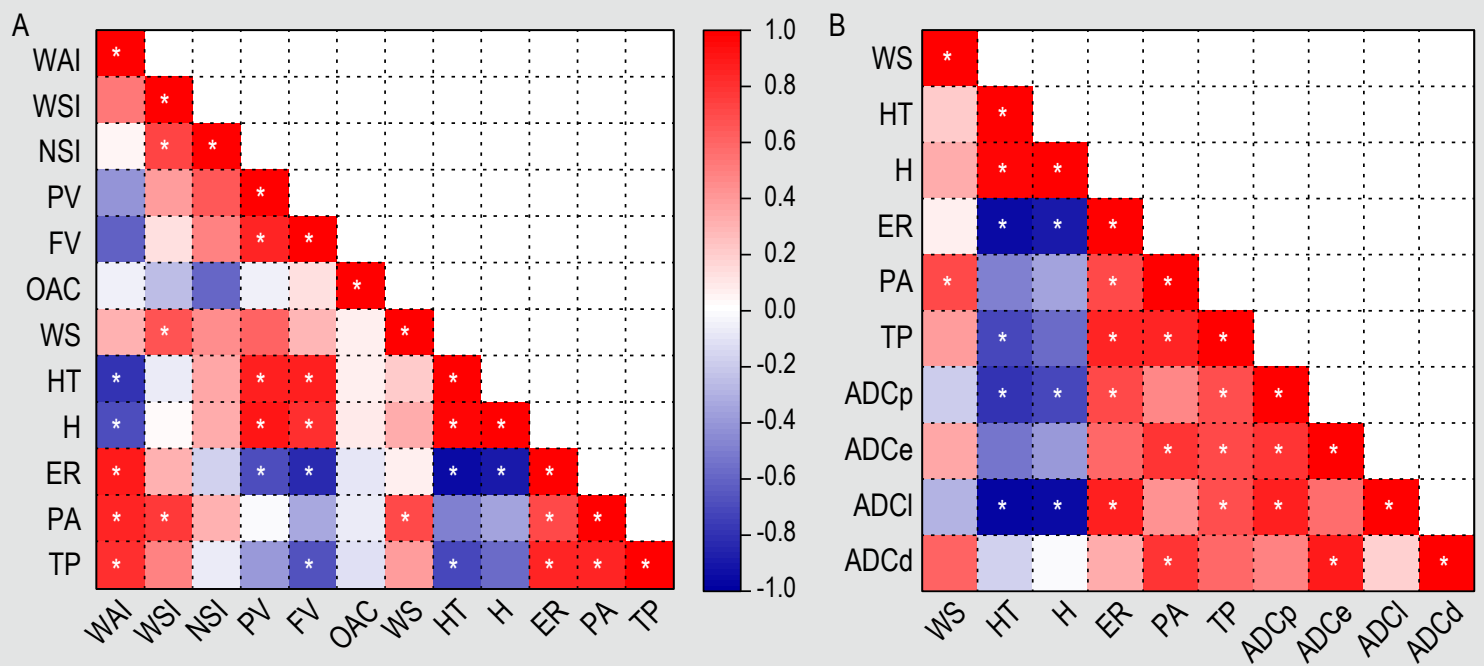

Figure 2. Correlation analysis (A) the correlation analysis between the physical qualities of extruded floating diet with physiochemical properties of the raw recipe formulations; $(B)$ the correlation analysis between the physical qualities of extruded floating diet with apparent digestibility coefficient. $A D C_{d}=A D C$ of $D M ; A D C_{e}=A D C$ of $G E ; A D C_{1}=A D C$ of $C L ; A D C_{p}=A D C$ of CP; ER = expansion rate; $\mathrm{FV}=$ final-viscous; $\mathrm{H}=$ hardness; $\mathrm{HT}=$ hydration time; $\mathrm{NSI}=$ nitrogen solubility index; $\mathrm{OAC}=$ oil absorption capacity; $\mathrm{PA}=$ pore area; $\mathrm{PV}=$ peak-viscous; $\mathrm{TP}=$ total porosity; $\mathrm{WAI}=$ water absorption index; $\mathrm{WS}=$ water stability; $\mathrm{WSI}=$ water solubility index. The white symbols * represent a significant correlation $(P<0.05)$. The white areas represent an uncorrelated relationship. The red areas represent the positive relationship, and the blue areas represent the negative relationship. 
The correlation analysis between the physical qualities of extruded floating diet with apparent digestibility coefficient are presented in Figure 2B and Table S2. Both obviously show that the hydration time and hardness were significantly negatively correlated with the $\mathrm{ADC}_{\mathrm{p}}$ and $\mathrm{ADC}_{1}(P<0.05)$. The expansion rate of the diets had a strong positive correlation with the $\mathrm{ADC}_{\mathrm{p}}$ and $\mathrm{ADC}_{\mathrm{l}}$ $(P<0.05)$. The pore area of the diets had a strong positive correlation with the $\mathrm{ADC}_{\mathrm{e}}$ and $\mathrm{ADC}_{\mathrm{d}}(P<0.05)$. The total porosity of the diets had a strong positive correlation with the $\mathrm{ADC}_{\mathrm{p}}, \mathrm{ADC}_{\mathrm{e}}$ and $\mathrm{ADC}_{1}(P<0.05)$.

\section{Discussion}

\section{Physical qualities and micro-structure of feed pellets}

From Table 5, it can be seen that the expansion rate and oil absorption capacity of diet YM50 were increased. However, the expansion rate of diet YM100 decreased. The correlation analysis results in Figure 2 show that the WAI has a strong positive correlation with the expansion rate and a strong negative correlation with the hydration time and hardness. However, the correlation between viscosity and qualities of feed pellets (expansion rate, hydration time and hardness) is exactly the opposite of the above. In this study, the raw recipe formulation of YM50 has a higher WAI than that of other groups, while the raw recipe formulation of YM100 shows higher pasting properties (Table 4). The WAI indicates the ability to retain the water of the diets, reflecting the water binding ability of the material (Lourenco et al., 2016). As a universal plasticiser in foods, water can improve processability, cooking efficiency in the extrusion process, and final product performance of feed pellets (Hudson and Daubert, 2002; Oterhals and Samuelsen, 2015; Samuelsen et al., 2013). Typically, a plasticiser may increase molecular mobility and reduce the glass and the melt transition temperature of biopolymers (Abiad et al., 2009; Di Gioia and Guilbert, 1999; Igura et al., 1997). Therefore, the raw recipe formulation of YM50 has a higher WAI, which means that it has increased hydration with water. This can also explain the high qualities of YM50 diet. However, the reason for the high WAI of YM50 will continue to be observed in the next phase of molecular structure research. In the aspect of raw material pasting properties, studies have shown that excessive softening of the melt limits the expansion of the material (AmayaLlano et al., 2007; Cha et al., 2001; Chanvrier et al., 2007). At the same time, the high viscosity of the melt increases specific mechanical energy and the roughness of the surface of the pellet (Draganovic et al., 2014). Singh et al. (2014) shown that the decrease in pasting properties, thus favouring the formation and maintenance of melt pore bubbles, increases the floatation rate. From the trial results, the pasting properties increased with the increase of YM contents in the diets. The high pasting properties of the YM100 raw recipe formulation led to poor qualities of pellet results. Under the same processing conditions with the same moisture content, the raw recipe formulation of the YM100 group has a higher viscosity than the other groups. This phenomenon can be balanced by increasing the moisture content (Draganovic et al., 2011, 2014).

The micro-structure of the pellets can reflect the extrusion effect of the pellets. The extrusion feed pellets with a high expansion rate usually have high pore porosity. The number and area of pores on the pellets directly affect the floatability of the pellets. (Alcaraz et al., 2021; De Cruz et al., 2015). Table 6 indicates that the pore area and total porosity of the diet YM50 are significantly higher than those of the YM0 and YM100. Thus, the YM50 has the best pore microstructure, which is characterised by high porosity and pore area. As can be seen from Figure 1 the diet YM0 has a higher number of pores and a smaller average pore size, while the diet YM100 has a lower number of pores and a larger average pore area. This is consistent with the data of bulk density and expansion rate. As with the physical qualities of feed, it may also be due to the high WAI and suitable pasting properties of YM50 which is conducive to the production of high-quality pore structures. However, the high pasting properties of YM100 make the extrudate a more rigid structure, thereby limiting the generation of pore structure (Lazou and Krokida, 2010). In the production of aquatic extruded floating feeds, oil in the formula is added mostly by spraying after vacuum. Therefore, the OAC and OL are important indicators of evaluation for floating extruded feed. The micro-structure such as the evenness of the outer surface and the permeability of the outer layer of the pellets play a fundamental role in the oilinfiltration pattern (Bouchon and Pyle, 2004). In this study, the oil absorption capacity of the diets YM0 and YM50 was higher than that of the YM100, and the oil leakage rate of diet YM100 was the lowest value. The diet YM50 has the best total porosity and expansion rate to provide the greatest oil absorption rate, which is similar to the results of Glencross et al. (2010). The YM100 group has less porosity and poor interconnection (thick pore walls) between the pores, resulting in a reduction in oil absorption, thereby reducing oil leakage (Alcaraz et al., 2021). Once the oil is injected into the ball with a vacuum, the lower pore interconnectivity and less fragmented structure also hinder fat leakage (Draganovic et al., 2013).

\section{Growth performance and apparent digestibility coefficients}

From Table 7, the growth performance of the YM50 group were not significantly different compared to the YM0 group. In addition, the YM100 group had a negative impact on the growth performance of the largemouth bass. The reasonable level of fishmeal replacement with YM depends on the different species and the growth stages of the experimental subjects according to their different 
nutritional requirements (Kim et al., 1991; Rahimnejad et al., 2015). Gasco et al. (2016) found that the replacement of $25 \%$ of fishmeal with YM in the diets of European sea bass did not adversely affect its growth performance, but the growth performance was compromised when YM replacement levels reached $50 \%$. While in rainbow trout diets, replacing 25-50\% of fishmeal with YM could improve the growth performance of the rainbow trout (Belforti et al., 2015). However, complete substitute of fishmeal with YM would reduce the WG of common catfish (Roncarati et al., 2015). The present study results are in agreement with the results of Roncarati et al. (2015). The YM50 group does not compromise the fish growth performance. However, the YM100 group has a negative impact on the growth performance of the largemouth bass. The YM may be a potential alternative source of fishmeal in terms of its positive effect on the growth performance of fish. This may contribute to the composition of YM, whose protein content and limited amino acids similar to fishmeal (Henry et al., 2015). Meanwhile, chitin in insect epidermis was present in a matrix containing proteins, lipids, and other compounds (Chapman, 1998; Kramer et al., 1995; Tharanathan and Kittur, 2003). Previous studies reported that a reduction in the SGR of juvenile fish, where feeding diets containing black soldiers fly with chitin (1.6-7\%) (Kroeckel et al., 2012). Shiau and Yu (1999) also reported that diets contain 2-10\% (wt) chitin resulted in a reduced weight gain in tilapia. In the study (Table 1), the chitin content in YM was 14\% (wt, based on the dry matter). Such high chitin content in the YM100 group may be the main reason for the lower FCR in the growth performance of the largemouth bass, which is similar to the results of Roncarati et al. (2015).

In the study, Table 7 shows that the nutrient digestibility (crude protein, crude lipid and gross energy) of the YM100 group were lower than those of the YM0 and YM50 groups, which may be due to its excessive content of chitin in YM ingredient. Chitinases hydrolyse the polymer chitin to the level of disaccharides and trisaccharides, which in turn are broken down by chitinases to the sugar monomer $\beta-\mathrm{N}$ acetyl-D-glucosamine (Danulat, 1987; Jeuniaux, 1963). Although, the reported chitinases are mainly present in the stomach and gut contents of fish that are chronic predators of crustaceans, degradation by chitinases appears to be limited in most fish (Kroeckel et al., 2012; Magalhães et al., 2017). Meanwhile, indigestible chitin may reduce the acquisition of digestive enzymes, thereby interfere with and reduce nutrients ADC (Henry et al., 2015). Studies have shown that feeds containing chitin reduce nutrient digestibility in Atlantic salmon (Hansen et al., 2010; Karlsen et al., 2017). A study by Kroeckel et al. (2012) showed that juvenile turbot diets containing 33\% defatted black soldier fly larval meal as a fishmeal substitute results in lower apparent digestibility of the fish. Some investigations also reported that chitin tends to reduce the water-holding capacity of digesta, increase faecal bulking and reduce intestinal transit time, thereby hardening the action of digestive enzymes, while nutrients such as amino acids bound to chitin caused its digestive capacity to be weakened (Dias et al., 1998; Finke, 2007; Henry et al., 2015; Magalhães et al., 2017; Piccolo et al., 2017). In our study, the $\mathrm{ADC}_{\mathrm{p}}$, $\mathrm{ADC}_{\mathrm{d}}, \mathrm{ADC}_{\mathrm{e}}$, and $\mathrm{ADC}_{1}$ in the YM50 group were higher than those in the YM0 and YM100 groups. As shown in Figure 1, in the micro-structure of the YM50 diet, the pore area and porosity were the highest. The micro-structure of extruded pellet feed was also a key factor affecting digestibility. This is also consistent with the results of the correlation analysis between micro-structure of feed pellets and ADC of nutrients in Figure 2B. Chanvrier et al. (2007) hypothesised that the micro-structure might govern the accessibility of digestive enzymes to macromolecules, thereby controlling their digestion. The study of Azzollini et al. (2018) studied that due to high porosity and small wall thickness, the YM addition levels of $0 \%$ and $10 \%$ groups produced a high surface contact area and consequently higher diffusion of enzymes. In contrast, it also observed that the lower digestibility of the pellets obtained with the addition of $20 \%$ of YM might be due to higher compactness, which leads to a decrease in enzyme accessibility (Azzollini et al., 2018). The lower porosity and thicker pore walls of the micro-structure of the YM100 group in this study might also be one of the important reasons affecting the digestibility, which is a match with the observation of Karkle et al. (2012). The correlation analysis of this study shows that hydration time and hardness was significantly negatively correlated with $\mathrm{ADC}_{\mathrm{p}}$ and $\mathrm{ADC}_{\mathrm{l}}$. This may be because the feed with high hardness and hydration time makes the diffusion of digestive enzymes into its interior slower, hindering the gastric emptying, leaching loss, and non-synchronous absorption of pellet feed (Wei et al., 2019; Zhang et al., 2019). It has also been reported that the increase in pore cell wall and the decrease in porosity will increase the hardness and hydration time of the pellets (Ahmad et al., 2019; Luo et al., 2020). This is also consistent with the trend of microstructure and digestibility analysis. In addition, from Table 1, the WSI of YM was higher than that of fish meal, and the increase of WSI may increase the digestibility of nutrients. It may also be an important reason for the higher digestibility of the YM50 group, which is similar to the results of Irungu et al. (2018).

Based on the results of growth performance and digestibility, the digestibility of the YM50 group was even slightly higher than that of the YM0 group, and without significant difference in feed intake were observed. However, the growth performance of the YM50 group were still lower, which may be due to that insect contain antimicrobial peptides (AMPs). Wang et al. (2021) studied that high dose of AMPs may not improve growth performance, but rather act inhibit the growth of fish. It may be related to the energy over-consumption for immunostimulation (Klasing, 2007; Liu et al., 2020; Ming et al., 2020). Liu et al. (2020) reported 
that $400 \mathrm{mg} / \mathrm{kg}$ AMPs synthesised by genetic engineering inhibited the growth performance of grass carp, which with a highest immunity response simultaneously. Whether the decrease in growth performance in this trial was related to the antimicrobial peptide needs further study.

\section{Conclusion}

The study showed that the defatted YM can replace up to $50 \%$ of dietary fishmeal in diet formulation without compromising the growth performance or nutrient digestibility of the largemouth bass. Meanwhile, it can improve the expansion rate of the extruded floating diet. At $100 \%$ YM replacement for fishmeal, the physical qualities of the extruded floating diet and the growth performance were reduced. It has been demonstrated from the trials that in defatted YM, the expansion rate, hydration time, and hardness of the investigated diets had a strong correlation with the WAI and pasting properties of the raw recipe formulations, and a strong correlation with apparent digestibility coefficient of the fish.

\section{Supplementary material}

Supplementary material can be found online at https://doi. org/10.3920/JIFF2021.0125

Table S1. The correlation analysis between the physical qualities of extruded floating diet with physio-chemical properties of the raw recipe formulations.

Table S2. The correlation analysis between the physical qualities of extruded floating diet with nutritional data.

\section{Acknowledgements}

This study was supported by the National Key R\&D Program of China (2019YFD0900200 and 2018YFD0900400); National Natural Science Foundation of China (32172981 and 31902382); The Agricultural Science and Technology Innovation Program of CAAS, China (CAAS-ASTIP-2017FRI-08); and Beijing Technology System for Sturgeon and Salmonids (BAIC08-2021).

\section{Conflict of interest}

The authors declare no conflict of interest.

\section{Reference}

Abiad, M.G., Carvajal, M.T. and Campanella, O.H., 2009. A review on methods and theories to describe the glass transition phenomenon: applications in food and pharmaceutical products. Food Engineering Reviews 1: 105-132. https://doi.org/10.1007/s12393-009-9009-1
Ahmad, R., Oterhals, Å., Xue, Y., Skodvin, T. and Samuelsen, T.A., 2019. Impact of fish protein concentrate on apparent viscosity and physical properties of soy protein concentrate subjected to thermomechanical treatment. Journal of Food Engineering 259: 34-43.

Ahmed, M., Akter, M.S. and Eun, J.-B., 2010. Peeling, drying temperatures, and sulphite-treatment affect physicochemical properties and nutritional quality of sweet potato flour. Food Chemistry 121: 112-118.

Alcaraz, R., Hernandez-Contreras, A., Iglesias, P. and Hernandez, M.D., 2021. Effect of the inclusion of microalgae on the physical properties of extruded feed for gilthead seabream (Sparus aurata L.). Algal Research-Biomass Biofuels and Bioproducts 53: 102167. https://doi.org/10.1016/j.algal.2020.102167

Amaya-Llano, S.L., Hernandez, N.M., Tostado, E.C. and MartinezBustos, F., 2007. Functional characteristics of extruded blends of whey protein concentrate and corn starch. Cereal Chemistry 84: 195-201. https://doi.org/10.1094/cchem-84-2-0195

American Association of Cereal Chemists (AACC), 1995. Approved methods of the AACC, $9^{\text {th }}$ edition. Methods 46-23. AACC, St. Paul, MN, USA.

Anderson, R., 1982. Water absorption and solubility and amylograph characteristics of roll-cooked small grain products. Cereal Chemistry 59(4): 265-269.

Association of Official Agricultural Chemists (AOAC), 2006. Official methods of analysis. AOAC, Rockville, MD, USA.

Azzollini, D., Derossi, A., Fogliano, V., Lakemond, C. and Severini, C., 2018. Effects of formulation and process conditions on microstructure, texture and digestibility of extruded insect-riched snacks. Innovative Food Science \& Emerging Technologies 45: 344-353.

Baeverfjord, G., Refstie, S., Krogedal, P. and Asgard, T., 2006. Low feed pellet water stability and fluctuating water salinity cause separation and accumulation of dietary oil in the stomach of rainbow trout (Oncorhynchus mykiss). Aquaculture 261: 1335-1345. https://doi. org/10.1016/j.aquaculture.2006.08.033

Banjac, V., Vukmirovic, D., Pezo, L., Draganovic, V., Duragic, O. and Colovic, R., 2021. Impact of variability in protein content of sunflower meal on the extrusion process and physical quality of the extruded salmonid feed. Journal of Food Process Engineering 44: e13640. https://doi.org/10.1111/jfpe.13640

Barroso, F.G., De Haro, C., Sanchez-Muros, M.J., Venegas, E., MartinezSanchez, A. and Perez-Banon, C., 2014. The potential of various insect species for use as food for fish. Aquaculture 422: 193-201. https://doi.org/10.1016/j.aquaculture.2013.12.024

Belforti, M., Gai, F., Lussiana, C., Renna, M., Malfatto, V., Rotolo, L., De Marco, M., Dabbou, S., Schiavone, A., Zoccarato, I. and Gasco, L., 2015. Tenebrio molitor meal in rainbow trout (Oncorhynchus mykiss) diets: effects on animal performance, nutrient digestibility and chemical composition of fillets. Italian Journal of Animal Science 14: 4170. https://doi.org/10.4081/ijas.2015.4170

Biswas, A., Takakuwa, F., Yamada, S., Matsuda, A., Saville, R.M., LeBlanc, A., Silverman, J.A., Sato, N. and Tanaka, H., 2020. Methanotroph (Methylococcus capsulatus, Bath) bacteria meal as an alternative protein source for Japanese yellowtail, Seriola quinqueradiata. Aquaculture 529: 735700. 
Bouchon, P. and Pyle, D.L., 2004. Studying oil absorption in restructured potato chips. Journal of Food Science 69: E115-E122.

Cha, J.Y., Chung, D.S., Seib, P.A., Flores, R.A. and Hanna, M.A., 2001. Physical properties of starch-based foams as affected by extrusion temperature and moisture content. Industrial Crops and Products 14: 23-30. https://doi.org/10.1016/s0926-6690(00)00085-6

Chanvrier, H., Appelqvist, I.A.M., Bird, A.R., Gilbertt, E., Htoon, A., Li, Z., Lillford, P.J., Lopez-Rubio, A., Morell, M.K. and Topping, D.L., 2007. Processing of novel elevated amylose wheats: functional properties and starch digestibility of extruded products. Journal of Agricultural and Food Chemistry 55: 10248-10257. https://doi. org/10.1021/jf0718650

Chapman, R.F., 1998. The insects: structure and function. Cambridge University Press, Cambridge, UK.

Danulat, E., 1987. Digestibility of chitin in cod, Gadus morhua, in vivo. Helgoländer Meeresuntersuchungen 41: 425-436.

De Cruz, C.R., Kamarudin, M.S., Saad, C.R. and Ramezani-Fard, E., 2015. Effects of extruder die temperature on the physical properties of extruded fish pellets containing taro and broken rice starch. Animal Feed Science and Technology 199: 137-145. https://doi. org/10.1016/j.anifeedsci.2014.11.010

Di Gioia, L. and Guilbert, S., 1999. Corn protein-based thermoplastic resins: effect of some polar and amphiphilic plasticers. Journal of Agricultural and Food Chemistry 47: 1254-1261. https://doi. org/10.1021/jf980976j

Dias, J., Huelvan, C., Dinis, M.T. and Métailler, R., 1998. Influence of dietary bulk agents (silica, cellulose and a natural zeolite) on protein digestibility, growth, feed intake and feed transit time in European seabass (Dicentrarchus labrax) juveniles. Aquatic Living Resources 11: 219-226.

Draganovic, V., Boom, R.M., Jonkers, J. and Van der Goot, A.J., 2014. Lupine and rapeseed protein concentrate in fish feed: a comparative assessment of the techno-functional properties using a shear cell device and an extruder. Journal of Food Engineering 126: 178-189. https://doi.org/10.1016/j.jfoodeng.2013.11.013

Draganovic, V., Van der Goot, A.J., Boom, R. and Jonkers, J., 2013. Wheat gluten in extruded fish feed: effects on morphology and on physical and functional properties. Aquaculture Nutrition 19: 845-859. https://doi.org/10.1111/anu.12029

Draganovic, V., Van der Goot, A.J., Boom, R. and Jonkers, J., 2011. Assessment of the effects of fish meal, wheat gluten, soy protein concentrate and feed moisture on extruder system parameters and the technical quality of fish feed. Animal Feed Science and Technology 165: 238-250. https://doi.org/10.1016/j. anifeedsci.2011.03.004

Fawole, F.J., Adeoye, A.A., Tiamiyu, L.O., Ajala, K.I., Obadara, S.O. and Ganiyu, I.O., 2020. Substituting fishmeal with Hermetia illucens in the diets of African catfish (Clarias gariepinus): effects on growth, nutrient utilization, haemato-physiological response, and oxidative stress biomarker. Aquaculture 518: 734849.

Finke, M.D., 2007. Estimate of chitin in raw whole insects. Zoo Biology 26: 105-115.
Gasco, L., Henry, M., Piccolo, G., Marono, S., Gai, F., Renna, M., Lussiana, C., Antonopoulou, E., Mola, P. and Chatzifotis, S., 2016. Tenebrio molitor meal in diets for European sea bass (Dicentrarchus labrax L.) juveniles: growth performance, whole body composition and in vivo apparent digestibility. Animal Feed Science and Technology 220: 34-45. https://doi.org/10.1016/j. anifeedsci.2016.07.003

Glencross, B., Hawkins, W., Maas, R., Karopoulos, M. and Hauler, R., 2010. Evaluation of the influence of different species and cultivars of lupin kernel meal on the extrusion process, pellet properties and viscosity parameters of salmonid feeds. Aquaculture Nutrition 16: 13-24. https://doi.org/10.1111/j.1365-2095.2008.00636.x

Hansen, J.Ø., Penn, M., Øverland, M., Shearer, K.D., Krogdahl, Å., Mydland, L.T. and Storebakken, T., 2010. High inclusion of partially deshelled and whole krill meals in diets for Atlantic salmon (Salmo salar). Aquaculture 310: 164-172.

Hardy, R.W., 2010. Utilization of plant proteins in fish diets: effects of global demand and supplies of fishmeal. Aquaculture Research 41: 770-776.

Henry, M., Gasco, L., Chatzifotis, S. and Piccolo, G., 2018. Does dietary insect meal affect the fish immune system? The case of mealworm, Tenebrio molitor on European sea bass, Dicentrarchus labrax. Developmental \& Comparative Immunology 81: 204-209.

Henry, M., Gasco, L., Piccolo, G. and Fountoulaki, E., 2015. Review on the use of insects in the diet of farmed fish: past and future. Animal Feed Science and Technology 203: 1-22. https://doi.org/10.1016/j. anifeedsci.2015.03.001

Hudson, H.M. and Daubert, C.R., 2002. Functionality comparison between derivatized whey proteins and a pregelatinized starch. Journal of Texture Studies 33: 297-314. https://doi. org/10.1111/j.1745-4.603.2002.tb01351.x

Ido, A., Hashizume, A., Ohta, T., Takahashi, T., Miura, C. and Miura, T., 2019. Replacement of fish meal by defatted yellow mealworm (Tenebrio molitor) larvae in diet improves growth performance and disease resistance in red seabream (Pargus major). Animals 9: 100.

Igura, N., Nakashima, D., Hayakawa, I. and Fujio, Y., 1997. Effect of moisture content and applied pressure on flow-starting temperature of starch melts. Journal of Food Engineering 31: 271-276. https:// doi.org/10.1016/s0260-8774(96)00083-0

Irungu, F., Mutungi, C., Faraj, A., Affognon, H., Kibet, N., Tanga, C., Ekesi, S., Nakimbugwe, D. and Fiaboe, K., 2018. Physico-chemical properties of extruded aquafeed pellets containing black soldier fly (Hermetia illucens) larvae and adult cricket (Acheta domesticus) meals. Journal of Insects as Food and Feed 4: 19-30.

Jeuniaux, C., 1963. Chitine et chitinolyse: un chapitre de la biologie moléculaire. Masson et Cie, Paris, France.

Karkle, E.L., Keller, L., Dogan, H. and Alavi, S., 2012. Matrix transformation in fiber-added extruded products: impact of different hydration regimens on texture, micro-structure and digestibility. Journal of Food Engineering 108: 171-182.

Karlsen, Ø., Amlund, H., Berg, A. and Olsen, R.E., 2017. The effect of dietary chitin on growth and nutrient digestibility in farmed Atlantic cod, Atlantic salmon and Atlantic halibut. Aquaculture Research 48: 123-133. 
Khater, E.-S.G., Bahnasawy, A.H. and Ali, S.A., 2014. Physical and mechanical properties of fish feed pellets. Journal of Food Processing \& Technology 5: 10.

Kim, K.I., Kayes, T.B. and Amundson, C.H., 1991. Purified diet development and re-evaluation of the dietary protein requirement of fingerling rainbow trout (Oncorhynchus mykiss). Aquaculture 96: 57-67. https://doi.org/10.1016/0044-8486(91)90139-x

Klasing, K., 2007. Nutrition and the immune system. British Poultry Science 48: 525-537.

Kramer, K.J., Hopkins, T.L. and Schaefer, J., 1995. Applications of solids NMR to the analysis of insect sclerotized structures. Insect Biochemistry and Molecular Biology 25: 1067-1080. https://doi. org/10.1016/0965-1748(95)00053-4

Kroeckel, S., Harjes, A.-G., Roth, I., Katz, H., Wuertz, S., Susenbeth, A. and Schulz, C., 2012. When a turbot catches a fly: evaluation of a pre-pupae meal of the black soldier fly (Hermetia illucens) as fish meal substitute - growth performance and chitin degradation in juvenile turbot (Psetta maxima). Aquaculture 364: 345-352.

Lazou, A. and Krokida, M., 2010. Structural and textural characterization of corn-lentil extruded snacks. Journal of Food Engineering 100: 392-408.

Le Feon, S., Thévenot, A., Maillard, F., Macombe, C., Forteau, L. and Aubin, J., 2019. Life cycle assessment of fish fed with insect meal: case study of mealworm inclusion in trout feed, in France. Aquaculture 500: 82-91.

Liu, S., Wang, J., Feng, Y., Ye, Q., Wen, L., Xu, G. and Zou, J., 2020. Effects of compound antimicrobial peptides on the growth performance, antioxidant and immune responses and disease resistance of grass carp (Ctenopharyngodon idellus). Fish \& Shellfish Immunology 107: 163-170. https://doi.org/10.1016/j.fsi.2020.09.042

Lourenco, L.F.H., Tavares, T.S., Araujo, E.A.F., Pena, R.S., Peixoto Joele, M.R.S. and Carvalho, A.V., 2016. Optimization of extrusion process to obtain shrimp snacks with rice grits and polished rice grains. Cyta - Journal of Food 14: 340-348. https://doi.org/10.108 0/19476337.2015.1114025

Luo, S., Chan, E., Masatcioglu, M.T., Erkinbaev, C., Paliwal, J. and Koksel, F., 2020. Effects of extrusion conditions and nitrogen injection on physical, mechanical, and microstructural properties of red lentil puffed snacks. Food and Bioproducts Processing 121: 143-153.

Magalhães, R., Sánchez-López, A., Leal, R.S., Martínez-Llorens, S., Oliva-Teles, A. and Peres, H., 2017. Black soldier fly (Hermetia illucens) pre-pupae meal as a fish meal replacement in diets for European seabass (Dicentrarchus labrax). Aquaculture 476: 79-85.

Miles, R.D. and Chapman, F.A., 2006. The benefits of fish meal in aquaculture diets. Department of Fisheries and Aquatic Sciences, University of Florida, Gainesville, FL, USA.

Mina-Boac, J., Maghirang, R.G. and Casada, M.E., 2006. Durability and breakage of feed pellets during repeated elevator handling. 2006 ASAE Annual Meeting. Paper number 066044. American Society of Agricultural and Biological Engineers, St. Joseph, MI, USA.
Ming, J., Ye, J., Zhang, Y., Xu, Q., Yang, X., Shao, X., Qiang, J. and Xu, P., 2020. Optimal dietary curcumin improved growth performance, and modulated innate immunity, antioxidant capacity and related genes expression of NF-kappa B and Nrf2 signaling pathways in grass carp (Ctenopharyngodon idella) after infection with Aeromonas hydrophila. Fish \& Shellfish Immunology 97: 540-553. https://doi. org/10.1016/j.fsi.2019.12.074

Ojha, S., Bußler, S., Psarianos, M., Rossi, G. and Schlüter, O., 2021. Edible insect processing pathways and implementation of emerging technologies. Journal of Insects as Food and Feed 7: 877-900.

Oterhals, A. and Samuelsen, T.A., 2015. Plasticization effect of solubles in fishmeal. Food Research International 69: 313-321. https://doi. org/10.1016/j.foodres.2014.12.028

Ottoboni, M., Spranghers, T., Pinotti, L., Baldi, A., De Jaeghere, W. and Eeckhout, M., 2018. Inclusion of Hermetia Illucens larvae or prepupae in an experimental extruded feed: process optimisation and impact on in vitro digestibility. Italian Journal of Animal Science 17: 418-427.

Piccolo, G., Iaconisi, V., Marono, S., Gasco, L., Loponte, R., Nizza, S., Bovera, F. and Parisi, G., 2017. Effect of Tenebrio molitor larvae meal on growth performance, in vivo nutrients digestibility, somatic and marketable indexes of gilthead sea bream (Sparus aurata). Animal Feed Science and Technology 226: 12-20.

Ragaee, S. and Abdel-Aal, E.-S.M., 2006. Pasting properties of starch and protein in selected cereals and quality of their food products. Food Chemistry 95: 9-18.

Rahimnejad, S., Bang, I.C., Park, J.Y., Sade, A., Choi, J. and Lee, S.M., 2015. Effects of dietary protein and lipid levels on growth performance, feed utilization and body composition of juvenile hybrid grouper, Epinephelus fuscoguttatus $\times$ E-lanceolatus. Aquaculture 446: 283-289. https://doi.org/10.1016/j. aquaculture.2015.05.019

Rema, P., Saravanan, S., Armenjon, B., Motte, C. and Dias, J., 2019. Graded incorporation of defatted yellow mealworm (Tenebrio molitor) in Rainbow trout (Oncorhynchus mykiss) diet improves growth performance and nutrient retention. Animals 9: 187. https:// doi.org/10.3390/ani9040187

Renna, M., Schiavone, A., Gai, F., Dabbou, S., Lussiana, C., Malfatto, V., Prearo, M., Capucchio, M.T., Biasato, I., Biasibetti, E., De Marco, M., Brugiapaglia, A., Zoccarato, I. and Gasco, L., 2017. Evaluation of the suitability of a partially defatted black soldier fly (Hermetia illucens L.) larvae meal as ingredient for rainbow trout (Oncorhynchus mykiss Walbaum) diets. Journal of Animal Science and Biotechnology 8: 57. https://doi.org/10.1186/s40104-017-0191-3

Roncarati, A., Gasco, L., Parisi, G. and Terova, G., 2015. Growth performance of common catfish (Ameiurus melas Raf.) fingerlings fed mealworm (Tenebrio molitor) diet. Journal of Insects as Food and Feed 1: 233-240. https://doi.org/10.3920/jiff2014.0006

Samuelsen, T. and Oterhals, Å., 2016. Water-soluble protein level in fishmeal affects extrusion behaviour, phase transitions and physical quality of feed. Aquaculture Nutrition 22: 120-133.

Samuelsen, T.A., Mjos, S.A. and Oterhals, A., 2013. Impact of variability in fishmeal physicochemical properties on the extrusion process, starch gelatinization and pellet durability and hardness. Animal Feed Science and Technology 179: 77-84. https://doi.org/10.1016/j. anifeedsci.2012.10.009 
Samuelsen, T.A., Mjos, S.A. and Oterhals, A., 2014. Influence of type of raw material on fishmeal physicochemical properties, the extrusion process, starch gelatinization and physical quality of fish feed. Aquaculture Nutrition 20: 410-420. https://doi.org/10.1111/ anu. 12093

Shiau, S.-Y. and Yu, Y.-P., 1999. Dietary supplementation of chitin and chitosan depresses growth in tilapia, Oreochromis niloticus $\times$ O. aureus. Aquaculture 179: 439-446.

Singh, R.K.R., Majumdar, R.K. and Venkateshwarlu, G., 2014. Optimum extrusion-cooking conditions for improving physical properties of fish-cereal based snacks by response surface methodology. Journal of Food Science and Technology 51: 1827-1836. https:// doi.org/10.1007/s13197-012-0725-9

Sipponen, M.H., Mäkinen, O.E., Rommi, K., Heiniö, R.-L., HolopainenMantila, U., Hokkanen, S., Hakala, T.K. and Nordlund, E., 2018. Biochemical and sensory characteristics of the cricket and mealworm fractions from supercritical carbon dioxide extraction and air classification. European Food Research and Technology 244: 19-29.

Smetana, S., Schmitt, E. and Mathys, A., 2019. Sustainable use of Hermetia illucens insect biomass for feed and food: attributional and consequential life cycle assessment. Resources Conservation and Recycling 144: 285-296. https://doi.org/10.1016/j. resconrec.2019.01.042

Son, Y.-J., Lee, J.-C., Hwang, I.-K., Nho, C.W. and Kim, S.-H., 2019. Physicochemical properties of mealworm (Tenebrio molitor) powders manufactured by different industrial processes. LWT 116: 108514

Stenberg, O.K., Holen, E., Piemontese, L., Liland, N.S., Lock, E.-J., Espe, M. and Belghit, I., 2019. Effect of dietary replacement of fish meal with insect meal on in vitro bacterial and viral induced gene response in Atlantic salmon (Salmo salar) head kidney leukocytes. Fish \& Shellfish Immunology 91: 223-232.

Tacon, A.G. and Metian, M., 2008. Global overview on the use of fish meal and fish oil in industrially compounded aquafeeds: trends and future prospects. Aquaculture 285: 146-158.

Tacon, A.G. and Metian, M., 2009. Fishing for aquaculture: non-food use of small pelagic forage fish - a global perspective. Reviews in Fisheries Science 17: 305-317.
Tharanathan, R.N. and Kittur, F.S., 2003. Chitin - the undisputed biomolecule of great potential. Critical Reviews in Food Science and Nutrition 43: 61-87. https://doi.org/10.1080/10408690390826455

Umar, S., Kamarudin, M. and Ramezani-Fard, E., 2013. Physical properties of extruded aquafeed with a combination of sago and tapioca starches at different moisture contents. Animal Feed Science and Technology 183: 51-55.

Van Huis, A. and Oonincx, D.G., 2017. The environmental sustainability of insects as food and feed. A review. Agronomy for Sustainable Development 37: 43.

Varotto Boccazzi, I., Ottoboni, M., Martin, E., Comandatore, F., Vallone, L., Spranghers, T., Eeckhout, M., Mereghetti, V., Pinotti, L. and Epis, S., 2017. A survey of the mycobiota associated with larvae of the black soldier fly (Hermetia illucens) reared for feed production. PLoS ONE 12: e0182533.

Wang, H., Ma, S., Yang, J., Qin, Y., Cheng, H., Xue, M., Li, J. and Li, J., 2021. Optimization of the process parameters for extruded commercial sinking fish feed with mixed plant protein sources. Journal of Food Process Engineering 44: e13599.

Wang, S., Xie, S., Zhou, A., Zhang, C., Wen, L., Xu, G. and Zou, J., 2021. Effects of mixed antimicrobial peptide on the growth performance, antioxidant and immune responses and disease resistance of Pengze crucian carp (Carassius auratus var. Pengze). Fish \& Shellfish Immunology 114: 112-118. https://doi.org/10.1016/j.fsi.2021.04.017

Wei, H., Chen, P., Liang, X., Yu, H., Wu, X., Han, J., Luo, L., Gu, X. and Xue, M., 2019. Plant protein diet suppressed immune function by inhibiting spiral valve intestinal mucosal barrier integrity, antioxidation, apoptosis, autophagy and proliferation responses in amur sturgeon (Acipenser schrenckii). Fish \& Shellfish Immunology 94: 711-722.

Weththasinghe, P., Hansen, J., Nøkland, D., Lagos, L., Rawski, M. and Øverland, M., 2021. Full-fat black soldier fly larvae (Hermetia illucens) meal and paste in extruded diets for Atlantic salmon (Salmo salar): effect on physical pellet quality, nutrient digestibility, nutrient utilization and growth performances. Aquaculture 530: 735785.

Zhang, Y., Chen, P., Liang, X., Han, J., Wu, X., Yang, Y. and Xue, M., 2019. Metabolic disorder induces fatty liver in Japanese seabass, Lateolabrax japonicas fed a full plant protein diet and regulated by cAMP-JNK/NF-kB-caspase signal pathway. Fish \& Shellfish Immunology 90: 223-234. 
